\title{
Analysis on Agricultural E-Commerce Platform Construction in Developed Areas Based on Rural Residents' Needs - Take the Case of Beijing*
}

\author{
Jian $\mathrm{Cao}^{1}$ and Yubin Wang ${ }^{2, * *}$ \\ ${ }^{1}$ Beijing University of Agriculture, Beijing, China \\ C_jcaojian@163.com \\ ${ }^{2}$ China Agricultural University, Beijing, China \\ wybecau .edu.cn
}

\begin{abstract}
This paper takes Beijing as an instance, launches investigation and survey on 152 rural residents, and analyzes the real demands of rural residents in the progress of e-commerce implementation in developed areas to provide government with support for the further construction in the relevant aspect. $71.71 \%$ of rural residents have ever heard about this concept, but among all the interviewees, $24.34 \%$ of them don't know what e-commerce is. There are $61.84 \%$ of rural residents who once conducted online shopping, but there are only $32.89 \%$ of rural residents having tried to sell or market their own agricultural products on the internet. Econometric model is used to find out the factors influencing rural residents to choose E-commerce. Rural residents with younger age are more willing to launch agricultural business through e-business, rural residents with higher annual income are more willing to attempt; and the ones with experiences of e-commerce online shopping are more willing to accept e-commerce of agricultural products. These suggestions are to provide with more trial opportunities and to provide rural residents with more training opportunities.
\end{abstract}

Keywords: E-Commerce Platform, Agricultural E-Commerce, Rural Residents' Needs, Influence Factors.

Agriculture is based on production, which is determined by two important factors: market and circulation. Information technology, network technology and e-commerce, such a new business pattern have injected new vitality and vigor into the circulation of agricultural products in China. The agricultural e-commerce has inspired the government and the society to promote the agriculture modernization in China to realize the great-leap-forward development of agriculture.

The agriculture modernization was put on the agenda since the 3rd Plenary Session of the 17th CPC. The informationized agriculture was increasingly valued, which brings a direction to the agriculture e-commerce. Since the development of e-commerce in the

\footnotetext{
Supported by the people's Republic of China Ministry of agriculture in 2012 special, Horticultural crop standard park to create result analysis and evaluation(No. 20125002).

** Corresponding author.
} 
late 20th century in China, agricultural e-commerce is no longer a new buzz word for Chinese, but its development has been limited greatly due to the immature conditions in all aspects. At present, the agriculture e-commerce is mainly headed by the government and the agricultural enterprises, while the individuals rarely go further under the present agricultural economic structure and confined by the capital condition. The government just advocates to promote the agriculture modernization by the agriculture industrialization and to optimize the agriculture industrialization by the agriculture informationization.

The agriculture informationization development in China achieved a lot during the past years. Yet, it is rarely researched on the topic what the proper information technology and e-commerce platform that the rural residents---the main users are in great need. In this article, the authors, taking 152 rural residents in Beijing as objects, analyze the real need of the rural residents in the developed rural areas in China, in order to provide a strong support for the further step related on such an issue.

\section{The Development Level of Agricultural Informationization and E-commerce Both in Beijing and China}

\subsection{Level of Agricultural Informationization in Beijing and China}

The development of agricultural e-commerce relies on agricultural informationization. As a weak industry, agriculture lags behind industry in terms of the development degree of informationization.

According to a report by CNNIC in January 2012, the number of the netizens in China has exceeded 50 million, reaching 51.3 million, and the Internet penetration has arrived at $38.3 \%$ by the end of 2011 . The rural netizen number in China is about 13.6 million, which is approximately equal to one third of that of the urban on the corresponding period of last year, and the Internet penetration is about equal to one sixth. Compared with the year of 2010, the proportion of rural netizens decreased by $0.8 \%$, its growth rate was still less than that of urban netizens. The number of the netizen who make a living on agriculture, such as farming, forestry, animal husbandry and fishery, takes about $4.0 \%$ of that of the total netizen, which means most of the rural residents in China don't surf online. The information services provided by agricultural websites can reach rural residents only if with the help of other information facilities or channels. The issue of information landing has become one of the bottlenecks restricting rural citizens from using information ${ }^{[1]}$. Beijing ranks top among other areas in China in terms of netizen popularity, its ratio is up to $70.3 \%$, doubling that of the national level. This means that the internet surfing level of rural citizens of Beijing also ranks top nationwide.

The proportion of administrative villages with internet access has been enhanced to 91.5\% (CNNIC, 2010). At present, the target of "four ones", namely "equip each village with one information service station, equip each town with one information service point, build one website for each village and launch one online program of agricultural and sideline products for each town", has been realized principally in 15 provinces. 


\subsection{The Current E-Commerce Situation on Agricultural Products}

According to the analysis of $\mathrm{Hu}$, there are seven business models of e-commerce of agricultural products in China, which can be sorted into three types: the first type are the primary ones, including catalog model, information model, medium model and virtual community model; the second type are the advanced models, including e-shop model, e-procurement model and value-chain integration model; the later type of models is the third party trading market model suitable for China's national conditions at the present stage ${ }^{[2]}$.

Currently, the application of the e-commerce of agricultural products can be classified into two types, the first is service provision of supply and demand information hosted by government, represented by http://www.agri.gov.cn/ (Chinese agriculture information network hosted by China's Ministry of Agriculture), and other agriculture related websites organized by governments at all levels. Websites hosted by governments also include the styles of B2B and B2C, such as http://12582.10086.cn/ (Nongxintong), http://www.118326.com/index.html (Info Village) and http://nxw.ln.10109555.com/web/index.asp (Jinnongtong) hosted by three basic telecommunications enterprises, and other basic comprehensive information platforms that have already covered the whole country. The second type is business service provision hosted by various economic entities. These websites mainly engage in providing with the service of commercial electronicalization of business links related to the production, supply and sales of agricultural products. Their main customers are enterprises with a certain scale. B2B and B2C are the major two forms being applied[1].

From the aspect of e-commerce application, there are a futures market for wheat, cotton and bean, etc, and a spot market online dealing with agricultural products. it has enlarged the online product category that includes poultry, vegetables, local specialty, flowers, fruits, aquatic products, tea and so on, instead of the former products mainly concerning on grain, oil and fertilizer.

However, from a research by CNNIC, the first five online applications of the rural netizens are online music, online news, online game, searching engine and instant messaging. The application of online games tops among the five and only $17.6 \%$ rural netizens has experienced online shopping. Therefore, it can be concluded that few rural netizens take a good advantage of the current agricultural e-commerce platform in China.

\section{The Recognition of the Rural Citizens on E-Commerce in Beijing}

\subsection{General Information of the Survey}

This survey is distributed to the suburb, including Haidian district (rural and urban fringe zones), Fangshan District, Tongzhou District, Shunyi District, Changping 
District, Daxing District, Huairou District and Pinggu District, and the exurban areas, including Yanqing County and Miyun County. There are 200 questionnaires totally, of which 152 are valid. There are $66.45 \%$ rural residents in plain areas and $33.55 \%$ in mountain areas and semi-mountain areas .

The following table 1 shows the basic character of the sample in this survey.

Table 1. The generalization of the survey

\begin{tabular}{lll}
\hline Item & & Ratio (\%) \\
\hline gender & male & 42.76 \\
& female & 57.24 \\
\hline age & below 20 & 6.58 \\
& $20-30$ & 35.53 \\
& $30-40$ & 20.39 \\
& $40-50$ & 26.32 \\
& $50-60$ & 7.24 \\
& Over 60 & 3.95 \\
\hline education & university/college and above & 34.87 \\
& high school & 24.34 \\
& middle school & 27.63 \\
& primary school & 10.53 \\
& below primary school & 2.63 \\
\hline job & the 1st industry & 55.92 \\
& the 3rd industry & 44.08 \\
\hline
\end{tabular}

Data Source: original survey, similarly hereinafter.

\subsection{The Information Facilities in Rural Areas}

The survey shows $88.16 \%$ of the rural residents have their own computer and $80.92 \%$ can surf online. That means $9.7 \%$ of the rural residents have not possessed the skills to surf online. Among those who surf online, $74.34 \%$ prefer to be online at home. This indicates the basic network building in Beijing is excellent, which will play a good role in promoting e-commerce.

Viewing from the internet access, at present, there are three ways including DUN (dial-up networking), ADSL and broadband. $79.53 \%$ of rural residents can log on the internet through broadband, showing that the internet speed is guaranteed to lay a foundation for the e-business.

With the popularity of internet, the channels for famers to get information have undergone great changes; internet has become the major information source of rural

${ }^{1}$ The $3^{\text {rd }}$ industry mainly refers to the leisure travel and service industry. 
residents, and there are $44.73 \%$ of rural residents choosing internet to gain information. But through our survey, we find that only 30 interviewees (accounted for $19.74 \%$ among all the interviewees) often surf on the relevant agriculture websites to gain information, showing that at present rural residents still haven't formed the habit of gaining information from professional agriculture websites, that is to say the first primary phase of e-commerce of agricultural products hasn't been universal among rural residents currently.

\subsection{The Recognition of the Rural Residents on E-Commerce}

The concept of "e-commerce" has been advocated in recent years that $71.71 \%$ rural residents have heard as the survey shows. However, there are different understandings. Among all the interviewees, $24.34 \%$ of them don't know what ecommerce is, $21.71 \%$ of them think e-commerce just means issuing relevant sales information on the internet, only $26.31 \%$ of them believe that e-commerce indicates "sales on the internet".

As to the question what will benefit the agricultural products by e-commerce, $46.05 \%$ rural residents believe they can learn more information and $28.95 \%$ think ecommerce will help them sell their products with good price.

Although rural residents can't figure out what is e-business, some of them have started practicing. There are $61.84 \%$ of rural residents who once conducted online shopping, but there are only $32.89 \%$ of rural residents having tried to sell or market their own agricultural products on the internet. Meanwhile, the passion among rural residents to sell through the model of e-commerce is not relatively high, accounting for less than $40 \%$ among all the rural residents.

\section{The Factors to the Rural Residents to Do E-Commerce}

Through this survey, we have found that rural residents' awareness of e-commerce is still vague at present. As a result, scene description to rural residents is needed before the research on the prerequisites influencing on rural residents when they are choosing the operation model of e-commerce. First, investigators explain the basic concept of e-commerce to rural residents in straightaway language, then describe to them the various advantages of e-commerce comparing to the traditional sales mode. After the situation description, conduct the investigation about whether rural residents are willing to use agricultural e-commerce platform as the main operation form.

In this survey, there are three options to the question of "Are you willing to sell your agricultural products or to get various commercial opportunities through ebusiness?", "Yes", "No" and "I don't care". In the data processing, "Yes" is defined as "1," "No" and "I don't care" are defined as "0". Therefore, the explained variable in researching on the e-commerce demand of rural residents is $(0,1)$; this paper chooses Logistic model for regression analysis.

When y takes a certain value (such as $y=1$ ), the relation between the probability of occurrence $(\mathrm{p})$ and some factors $(\mathrm{x})$ is as following: 


$$
P(y=1 / x), \text { ie. } p=f(x)
$$

$\mathrm{P}$ (probability) is valued between $0 \sim 1$.

The Logistics model is used with a grouped data to predict the relation between a number of $\mathrm{x}$ and a dependent variable with different values, thus, showing the reliable relationship.

The General Equation is as followed:

$$
y=\log i t(p)=\beta_{0}+\beta_{1} x_{1}+\cdots \beta_{n} x_{n}
$$

\subsection{Sample Selection}

Obviously, e-commerce is based on internet access, therefore, when discussing whether rural residents will choose e-commerce or not, we only select a subsample with 121 interviewees who have mastered the skills of surfing on the internet from the sample with152 interviewees.

\subsection{Variable Selection}

In general, the individual character, the related facilities and so on are what will be taken into consideration of the action of the rural residents. Therefore, we will focus on the following four factors in this article:

a. The individual character of the rural residents: Age, education, job and income of very month are taken as the dependent variables.

b. The situation of information infrastructure in rural areas: The distance to the county and the way to surf online as the dependent variables represent the situation of information infrastructure in rural areas.

c. The internet usage of the rural residents: Three options "Occasional", "often" and "every day" are taken to represent the online frequency.

d. The recognition on e-commerce of the rural residents: The question "have you ever shopped online" is indicated whether they know e-commerce, as it is hard for them to tell the concept of e-commerce.

\begin{tabular}{|c|c|c|c|}
\hline Variable Name & $\begin{array}{c}\text { Variable } \\
\text { Abbreviation }\end{array}$ & Variable Explanation & Variable Statistics \\
\hline Dependent Variable & $\mathrm{Y}$ & & Willing to use d-business \\
\hline Age & AGE & Physical Age & 33.44 \\
\hline Education & EDU & $\begin{array}{l}\text { Represented by } \\
\text { number of years one } \\
\text { receiving education }\end{array}$ & 12.49 \\
\hline
\end{tabular}

Table 2. Basic Information of Variables 
Table 2. (Continued)

\begin{tabular}{|c|c|c|c|}
\hline Industry & IND & $\begin{array}{l}\text { Rural residents } \\
\text { engaging in breeding } \\
\text { and cultivation are set } \\
\text { as 1, rural residents } \\
\text { engaging in other } \\
\text { tertiary industries are } \\
\text { set as 0 ( leisure and } \\
\text { sightseeing industry is } \\
\text { also regarded as } \\
\text { tertiary industry) }\end{array}$ & $\begin{array}{l}28.10 \% \text { are engaging in } \\
\text { primary industry }\end{array}$ \\
\hline $\begin{array}{l}\text { Annual Household } \\
\text { Income }\end{array}$ & INC & & 27851.24 \\
\hline $\begin{array}{l}\text { Distance between } \\
\text { home to County } \\
\text { Town }\end{array}$ & DIS & Unit: Kilometer & 24.79 \\
\hline $\begin{array}{l}\text { Internet Connection } \\
\text { Mode } 1\end{array}$ & MODE1 & DUN $=1$, Others $=0$ & $4.13 \%, \mathrm{UNI}$ \\
\hline $\begin{array}{l}\text { Internet Connection } \\
\text { Mode } 2\end{array}$ & MODE2 & $\mathrm{ADSL}=1$, others $=0$ & $12.40 \%, \mathrm{ADSL}$ \\
\hline $\begin{array}{l}\text { Internet-using } \\
\text { Frequency } 1\end{array}$ & FRE1 & $\begin{array}{l}\text { Occasionally }=1 \text {, } \\
\text { others }=0\end{array}$ & $\begin{array}{l}33.07 \%, \quad \text { occasionally } \\
\text { connecting to the internet }\end{array}$ \\
\hline $\begin{array}{l}\text { Internet-using } \\
\text { Frequency } 2\end{array}$ & FRE2 & Often $=1$, Others $=0$ & $\begin{array}{l}13.22 \% \text {, often connecting } \\
\text { to the internet }\end{array}$ \\
\hline $\begin{array}{l}\text { Have you ever } \\
\text { bought anything } \\
\text { through e-business? }\end{array}$ & BUY & $\mathrm{Yes}=1, \mathrm{No}=0$ & $\begin{array}{l}74.38 \% \text { once bought } \\
\text { something through e- } \\
\text { business }\end{array}$ \\
\hline
\end{tabular}

\subsection{Presumption to Be Testified}

a. The one who is younger and with higher education will be more likely to do e-commerce.

b. The one who has the e-commerce experience will be more likely to do ecommerce with the agricultural products.

c. The development of the internet will be a factor to affect e-commerce.

d. The one with a higher frequency will be more likely to do e-commerce.

\subsection{Assessment and Results}

We use EVIEWS7.0 to assess the model in this article. We find there is a great relation between the age and the education. Therefore, we eliminate the variable of education to make an assessment. The relative result is as following: 
Table 3. The result of the assessment

\begin{tabular}{lllll}
\hline Variable & Coefficient & Std. Error & z-Statistic & Prob. \\
\hline AGE & -0.052831 & 0.017224 & -3.067221 & 0.0022 \\
IND & 0.400549 & 0.489629 & 0.818066 & 0.4133 \\
INC & $2.49 \mathrm{E}-05$ & $1.40 \mathrm{E}-05$ & 1.782153 & 0.0747 \\
DIS & -0.005285 & 0.007459 & -0.708533 & 0.4786 \\
MODE1 & 0.424002 & 0.964057 & 0.439810 & 0.6601 \\
MODE2 & -0.567187 & 0.596467 & -0.950911 & 0.3416 \\
FRE1 & 0.460137 & 0.501401 & 0.917703 & 0.3588 \\
FRE2 & 0.061557 & 0.611150 & 0.100724 & 0.9198 \\
BUY & 1.194978 & 0.447902 & 2.667942 & 0.0076
\end{tabular}

Viewing from the estimation result, below the significance level of $10 \%$, there are three options including age, annual household income and the past experience of online shopping that show significance. That is to say rural residents with younger age are more willing to launch agricultural business through e-business, rural residents with higher annual income are more willing to attempt; and rural residents with experiences of e-commerce online shopping are more willing to accept ecommerce of agricultural products. Variables including internet connection mode and online frequency indicate insignificance.

\section{Conclusion and Further Discussion}

In developed areas (eg. Beijing), all the villages and towns have built up their own websites principally, the degree of convenience for rural residents to connect to the internet has been increased greatly; furthermore, most peasant households have had their own computers, mainly realizing the target of surging on the internet at home for rural residents. Under such background, the personal characteristic of a farmer, such as the age and income status, is the dominant factor influencing one's decision to launch online business of agricultural products or not.

Meanwhile, it is more acceptable for newly emerging things after some trying experience; thus appropriate increase of trial opportunities can be beneficial.

Through analysis, we can find that the internet speed doesn't significantly influence the application of e-commerce of agricultural products; therefore, hardware is not the main restrictive factor.

Based on the analysis above, we would like to propose some suggestions to the construction of e-commerce of agricultural products in China:

1. More attempts to do e-commerce with free charge should be provided by the platform.

With the attempts to do e-commerce, the rural residents will be encouraged and inspired, which will make a solid foundation for further development of the ecommerce on agricultural products.

2. More training should be provided to the rural residents. 
In the survey, $51.25 \%$ of the rural residents think what they need most is the training on e-commerce. It is the greatest investment in the aspect of the software after the platform as the hardware is finished.

\section{References}

1. Tianshi, H.: Study on E-commerce Business Model for Chinese Agricultural Products. Chinese Academy of Agricultural Sciences (2005)

2. Yanyan, H.: Study on the Countermeasures of Developing Electronic Business of Agricultural Produce_-A Case Study of Vegetables in Shouguang. Chinese Academy of Agricultural Sciences (2008) 